\title{
1 Implementing school policy effectively
}

\author{
Kelly-Ann Allen, Andrea Reupert, and \\ Lindsay Oades
}

\section{Introduction}

Evidence-based policies are critical to the way that contemporary schools are run. Policies serve regulatory functions, and may also create standards of quality for teaching and learning, and opportunities for authentic engagement of staff, students and communities. For the first time, this book brings together research from different disciplinary and international scholars to deliver practical, evidence-based policy for schools.

With policies written by leading scholars in their field, this book collects in one place a rigorous and comprehensive yet accessible compendium of policies that schools can use and adapt. The specialist expertise of the authors means that each policy identifies key principles and issues that need to be considered by school communities across different domains, and anchored in the empirical realities of teaching and learning.

The book provides new understandings in policy development and content for schools to immediately adapt and apply. This makes it unique amongst other contemporary, research-orientated books. The provision of evidencegrounded policy exemplars that forms the heart of the book means that the book is uniquely placed to start the conversation between researchers and schools, and bridge the research-practice schism.

This opening chapter will explain the rationale for the use of evidencebased policies in schools and the need for schools to be equipped with readyto-adapt policies. This chapter will also discuss why academics have a moral responsibility to translate and transform their work for the public. Finally, this chapter will detail how to consider the implantation issues related to the policies within the book. Readers will be given suggestions as to how they can most effectively use this book through adapting and tailoring policy to fit within their own unique schools and contexts.

\section{Schools need policy}

School leaders use policy to create standards, ensure consistency, support vision and mission statements, meet certain accreditation standards and/or 


\section{Allen, Reupert, \& Oades}

guide day-to-day practices (Allen et al., 2017; 2018). It is a requirement for most schools to have supporting policy that is, at a minimum, known and accessible to parents, staff, and in some circumstances, students. There is also a need for policy to remain current and in keeping with best practices (Efreom-Lieber \& Lieber, 2010; Magor-Blatch, 2011). Thus, there is an obligation for school leaders to review and update policy documents regularly. Notwithstanding the importance of policies for schools, the processes of writing and maintaining policy can be a significant burden on school leaders and their staff.

School leaders and staff are not always resourced or qualified to meet the demands required to effectively write or update school policy. In general, school staff report not having enough time to engage in policy writing and suggest they lack the required expertise. Moreover, training and professional development available for policy writing are variable or non-existent for many school staff.

\section{The problem with policy}

Schools face several systemic challenges when attempting to assemble and write solid policy documents. In general, teaching staff, including school leaders, report increased stress and burnout, and describe feeling undervalued and underpaid (Roffey, 2012). In the UK, an analysis of 27,500 teachers who trained between 2011 and 2015 found that a quarter had left the profession. Data from Australia captured through the Hunter Institute of Mental Health found that up to half of the 453 Australian teachers sampled leave the profession in the first five years after graduation. School staff report various stressors including long hours, high workloads, disruptive and overcrowded classrooms, an overemphasis on testing, prescriptive curricula, teaching subjects that they do not have content knowledge in, a lack of input into decision making and the unavailability of supports for students with additional needs (Bahr et al., 2018). In the United States, we see similar concerns. In fact, it has been estimated that in addition to the significant portion of teachers who leave the profession, up to $8 \%$ change schools. Teacher turnover rates pose a major challenge for school leadership (Carver-Thomas \& Darling-Hammond, 2019). Many of the concerns we see in the teaching profession are experienced globally. Writing policy documents, including identifying the appropriate data to inform these policies, provides yet another potentially onerous task for school staff.

Another issue stems from the fact that using research and evidence to improve practice is complex and skilled work that requires thoughtful engagement and appropriate evidence (Earl \& Timperley, 2009: Rickinson et al., 2020). It is not surprising, then, that there continue to be situations where the results of empirical research are not applied within practice and school policy (Hempenstall, 2006). This lag in knowledge is possibly why many 
schools still implement outdated educational practices not supported in the literature (e.g., the teaching of learning styles, reading recovery). There are many barriers affecting this, including problems related to leadership, culture and ethos, time, staff capability and a lack of training opportunities (Reupert, 2018; Prendergast \& Rickinson, 2019). Likewise, many school libraries do not have access to database subscriptions, making it difficult for school staff, such as teachers, to access research-driven knowledge.

In addition, though some school staff have access to information that can help inform common and generic policy statements (e.g., anaphylaxis, after school care or academic achievement), it is increasingly acknowledged that schools need to focus on the development of the whole student (Waters et al., 2017), a priority supported by most schools (Allen et al., 2018). This means that there is mounting pressure on schools to implement approaches towards building social and emotional competencies, positive relationships, a sense of school belonging and emotional wellbeing in students alongside attaining literacy and numeracy competencies. These kinds of priorities take educators into new areas of practice and policy development.

Overall, school leaders require policy documents to support whole-school, evidence-based approaches. Policy in such areas requires a high level of specific expertise that may not be easily available to schools. Building Better Schools with Evidence-based Policy: Adaptable Policy for Teachers and School Leaders provides schools with policy in areas that are not readily accessible and require specialised evidence-based knowledge. Policies that aim to build better schools take into consideration the whole student, in an evidencebased manner. Therefore, this book addresses a critical gap in school policy internationally.

From a different perspective, the research community needs to connect their research with the realities of the day-to-day running of schools. To do this, researchers need to find accessible ways of disseminating their work in a clear, succinct manner. Building Better Schools with Evidence-based Policy: Adaptable Policy for Teachers and School Leaders is designed to address the researchpractice gap by offering the best practice policy directly to schools in an accessible and useful way. Thus, the dual purpose of this book is to provide school leaders and staff with a useful, time-saving resource for building important policy and, at the same time, provide academics and researchers with a clear and effective vehicle for disseminating their research to the people who will benefit from it the most.

\section{How to use this book}

The policies to be included in this book cover a broad range of popular topics that are not readily accessible to schools, and each policy is built on theory, driven by research and created by policymakers and experts. Each policy is based on substantial evidence and this is ensured through the inclusion of 
contributors who are active and highly reputable in their respective field. Each policy is presented in a ready-to-use and adaptable format that includes guidelines for school policy makers to help guide them in removing and adapting text to create their own school-specific policy. The keyword here is adaptable. All policies within this book are designed to be adapted and tailored to the unique diversity and needs of each school as reflected by the context and the people that make up the school community.

All policy included in this book is free for schools to use as their own.

\section{The importance of evidence-based practice in schools}

Evidence-based practices are well established practices or interventions that have undergone a rigorous evaluation process and demonstrated effectiveness with specific population groups, for example, certain school communities, year levels or students with particular needs (Reupert, 2020). Rather than relying on the pendulum swings of fads and opinion, evidence-based practice relies on significant and reliable evidence, obtained by rigorous, replicable methods. Understanding and applying data-driven evidence provides an opportunity for genuine and sustainable structural change in the way we teach and support students. Commonly espoused as models of "gold standard", the use of datadriven, evidence-based practices typically identifies "what works" and, accordingly, is essential to driving policy and thereby continuous improvement in schools.

It is also important, though, to recognise that research evidence does not replace but rather complements the professional expertise of educators. In other words, the challenge is integrating professional expertise with the best external evidence from research in specific contexts (Sharples, 2013). This brings us on to the important challenge of implementation.

\section{Implementing policy with fidelity}

Most teachers would agree that it is not worthwhile having a terrific intervention or idea if nobody implements it. When implementing policy, it is important for schools to consider:

- How will key stakeholders be identified and how will they become actively involved in decisions related to the policy (particularly those decisions that affect them)?

- How does the policy need to be adapted to a particular school setting?

- How will information about school policy be disseminated to, and understood by, students, parents, teachers and school staff?

- What will the timeline for policy implementation look like and when can evaluation, feedback, monitoring or follow up occur?

- Is the concerned policy feasible? Does it match the skills and willingness of implementers? Is it appropriate for the available resources? 
- Do staff need short-term or long-term professional development or training to implement the policy for themselves and students?

Evidence for Learning (2019) provides best practice foundations for implementation that can be applied to the implementation of school policy. They suggest that schools engage in a six-stage process to effectively plan and implement school policy (Figure 1).

\section{Foundations for good implementation \\ $\checkmark$ Treat implementation as a process, not an event. Plan and execute it in stages. \\ $\checkmark$ Create a leadership environment and school climate that is conducive to good implementation.}

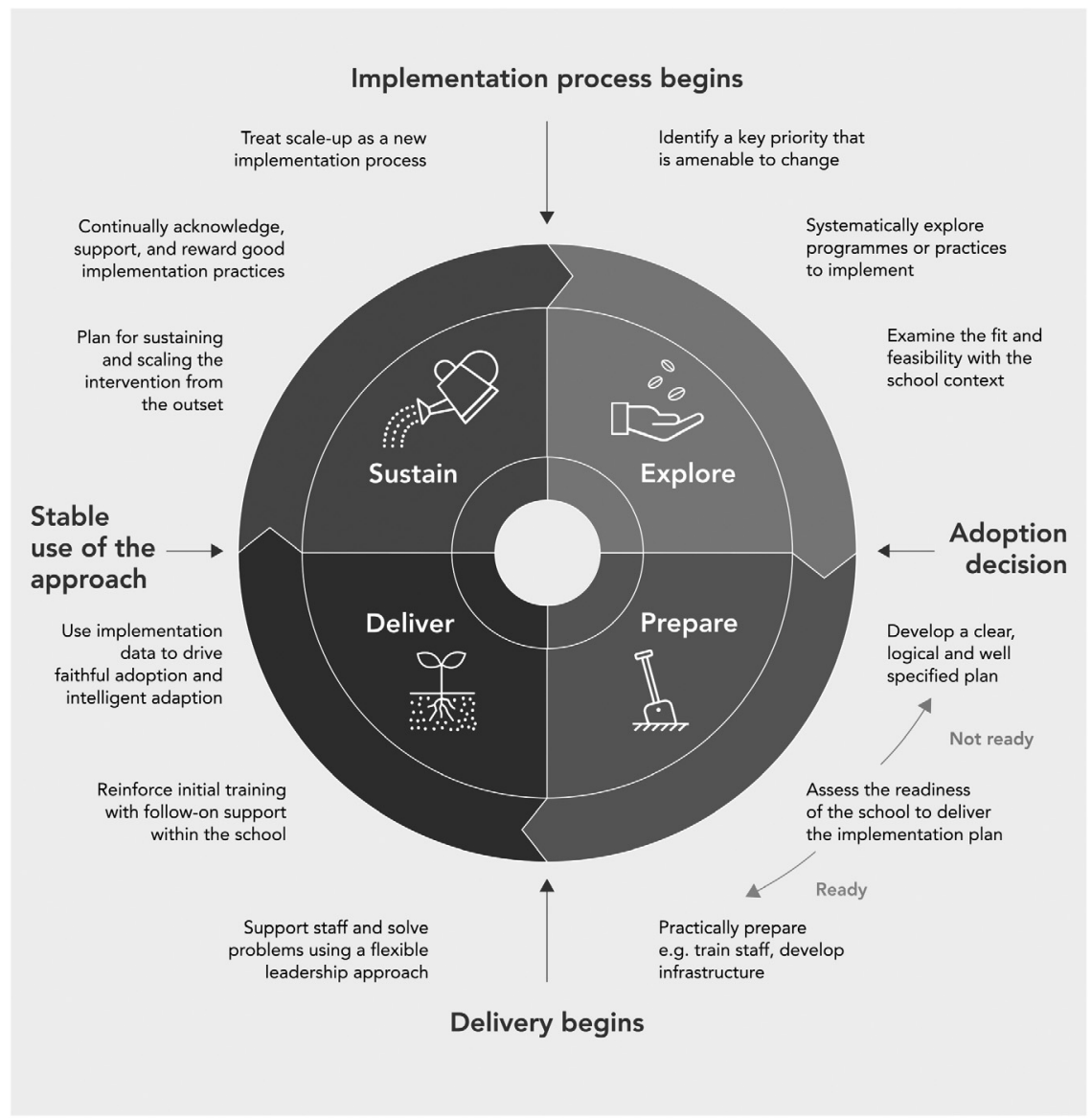

Figure 1: Implementation can be described as a series of stages relating to thinking about, preparing for, delivering, and sustaining change.

Figure 1.1. The stages of implementation.

Image provided with permission from Evidence for Learning (2019). 
The foundations for good implementation include (Adapted from Evidence for Learning, 2019):

1 Treat implementation as a process, not an event plan, and execute it in stages.

- Allow enough time for effective implementation, particularly in the preparation stage; prioritise appropriately.

2 Create a leadership environment and school climate that is conducive to good implementation.

- Set the stage for implementation through curriculum, routines and practices.

- Identify and cultivate leaders of implementation throughout the school.

- Build leadership capacity through implementation teams.

3 Define the problem you want to solve and identify appropriate programs or practices to implement.

- Specify a tight area of focus for improvement that is amenable to change.

- Determine a program of activity based on existing evidence of what has - and hasn't - worked before.

- Examine the fit and feasibility of possible interventions or policy to the school context.

- Make an adoption decision.

4 Create a clear implementation plan, judge the readiness of the school to deliver that plan, then prepare staff and resources.

Develop a clear, logical, and well-specified implementation plan:

a) Specify the active ingredients of the intervention clearly: Know where to be "tight" and where to be "loose".

b) Develop a targeted yet multi-stranded package of implementation strategies.

c) Define clear implementation outcomes and monitor them using robust and pragmatic measures.

- Thoroughly assess the degree to which the school is ready to implement the innovation or policy.

- Once ready to implement an intervention or policy, practically prepare for its use:

a) Create a shared understanding of the implementation process and provide appropriate support and incentives. 

b) Introduce new skills, knowledge and strategies with explicit upfront training.
c) Prepare the implementation infrastructure.

5 Support staff, monitor progress, solve problems and adapt strategies as the approach is used for the first time.

- Adopt a flexible and motivating leadership approach during the initial attempts at implementation.

- Reinforce initial training with follow-on coaching within the school.

- Use highly skilled coaches.

- Complement expert coaching and mentoring with structured peerto-peer collaboration.

- Use implementation data to actively tailor and improve the approach.

- Make thoughtful adaptations only when the active ingredients are securely understood and implemented.

6 Plan for sustaining and scaling an intervention from the outset and continuously acknowledge and nurture its use.

- Plan for sustaining and scaling an innovation from the outset.

- Treat scale-up as a new implementation process.

- Ensure the implementation data remains fit for purpose.

- Continuously acknowledge, support and reward good implementation practices.

(Adapted from Evidence for Learning, 2019, p. 6-7)

\section{Final thoughts}

All school policymakers should ensure that students and staff have sufficient buy-in to the creation and implementation of policies that most concern them. Parents, staff, students, school leaders and often the broad school community benefit from knowing and understanding about the utility of such policies. Schools must consider how their school policy will be adapted, shared, understood, enacted, used and reviewed. Too often, school policies are published and forgotten. School leaders need to take an active role in ensuring this does not happen. Evidence-based policy helps schools understand the important research base that drives best practices. This book includes a summary of the research evidence to ensure that policy users can understand the research base and methods that underpin the policy they are providing to their school. In sum, policies should be implemented intentionally, authentically and with fidelity. The following checklist from Evidence for Learning (2019) provides a summary: 


\section{Fidelity checklist for implementing policy}

- Plan and prepare. The implementation of a policy is a process, not an event.

- Set a conducive environment for effective implementation through strong leadership.

- Identify the problem you wish to address.

- Create a clear and concise implementation plan; assess the capacity of the school; train the staff and identify resources.

- Implement the policy; monitor the progress; revise where needed.

- Build sustainability into your implementation plan.

(Evidence for Learning, 2019, pp. 6-7)

Evidence-based policy is the foundation of effective school management and practices. But for school policies to work effectively and continuously improve, efficient planning and implementation are essential.

Dr Kelly-Ann Allen, PhD, Faculty of Education, Monash University and the Centre for Positive Psychology, Melbourne Graduate School of Education, The University of Melbourne

Professor Andrea Reupert, PhD, Faculty of Education, Monash University and The University of Melbourne

Professor Lindsay Oades, PhD, Centre for Positive Psychology, Melbourne Graduate School of Education, The University of Melbourne

\section{Acknowledgements}

We would like to acknowledge the consultation of Associate Professor Mark Rickinson, Monash University, for his assistance in the development of this chapter.

\section{References}

Allen, K. A., Kern, P., Vella-Brodrick, D., \& Waters, L. (2018). Understanding the priorities of Australian secondary schools through an analysis of their mission and vision statements. Educational Administration Quarterly, 54(2), 249-274.

Allen, K. A., Kern, M. L., Vella-Brodrick, D., \& Waters, L. (2017). School Values: A comparison of academic motivation, mental health promotion, and school belonging with student achievement. The Educational and Developmental Psychologist, 34(1), 31-47.

Bahr, N., Graham, A., Ferreira, J., Lloyd, M., \& Waters, R. (2018). Promotion of the teaching profession in Queensland. Prepared for Queensland College of Teachers. Bilinga: Southern Cross University. https://cdn.qct.edu.au/pdf/Promotion_TPQ.pdf

Carver-Thomas, D., \& Darling-Hammond, L. (2019). The trouble with teacher turnover: How teacher attrition affects students and schools. Education Policy Analysis Archives, 27(36). 
Earl, L. M., \& Timperley, H. (2009). Understanding how evidence and learning conversations work. In L. M. Earl \& H. Timperley (Eds.), Professional learning conversations (pp. 1-12). Dordrecht: Springer.

Efreom-Lieber, Y., \& Lieber, P. (2010). An ethical critique of suspension and zerotolerance policies. The Australian Educational and Developmental Psychologist, 27(2), 104-114.

Evidence for Learning. (2019). Putting evidence to work: A school's guide to implementation. Evidence for Learning.

Hempenstall, K. (2006). What does evidence-based practice in education mean? Australian Journal of Learning Disabilities, 11(2), 83-92.

Magor-Blatch, L. (2011). Beyond zero tolerance: Providing a framework to promote social justice and healthy adolescent development. The Australian Educational and Developmental Psychologist, 28(1), 61-74.

Prendergast, S., \& Rickinson, M. (2019). Understanding school engagement in and with research. The Australian Educational Researcher, 46(1), 17-39.

Reupert, A. (2018). Research that makes a difference. Advances in Mental Health, 16(2), 101-104.

Reupert, A. (2020). Mental health and academic learning in schools: Approaches for facilitating the wellbeing of children and young people. Taylor \& Francis.

Rickinson, M., Sharples, J., \& Lovell, O. (2020). Towards a better understanding of quality of evidence use. In S. Gorard (Ed.), Getting evidence into education: Evaluating the routes to policy and practice (pp. 218-233). Routledge.

Roffey, S. (2012). Pupil wellbeing - teacher wellbeing: Two sides of the same coin? Educational \& Child Psychology, 29(4), 8-17.

Sharples, J. (2013). Evidence for the frontline: A report for the Alliance for Useful Evidence. Alliance for Useful Evidence. https://www.alliance4usefulevidence.org/assets/ EVIDENCE-FOR-THE-FRONTLINE-FINAL-5-June-2013.pdf

Waters, L., Sun, J., Rusk, R., Cotton, A., \& Arch, A. (2017). Positive education: Visible wellbeing and positive functioning in students. In M. Slade, L. Oades \& A. Jarden (Eds.), Wellbeing, recovery and mental health (pp. 245-264). Cambridge University Press. 